\title{
The dilemma of differentiating between acute hepatitis $B$ and chronic hepatitis B with acute exacerbation: Is quantitative serology the answer?
}

\author{
Sujata Lall', Pragya Agarwala', Guresh Kumar², Manoj Kumar Sharma³ , and Ekta Gupta' \\ Departments of ${ }^{1}$ Clinical Virology, ${ }^{2}$ Clinical Research, ${ }^{3}$ Hepatology, Institute of Liver and Biliary Sciences, Delhi, India
}

\section{Graphical Abstract}

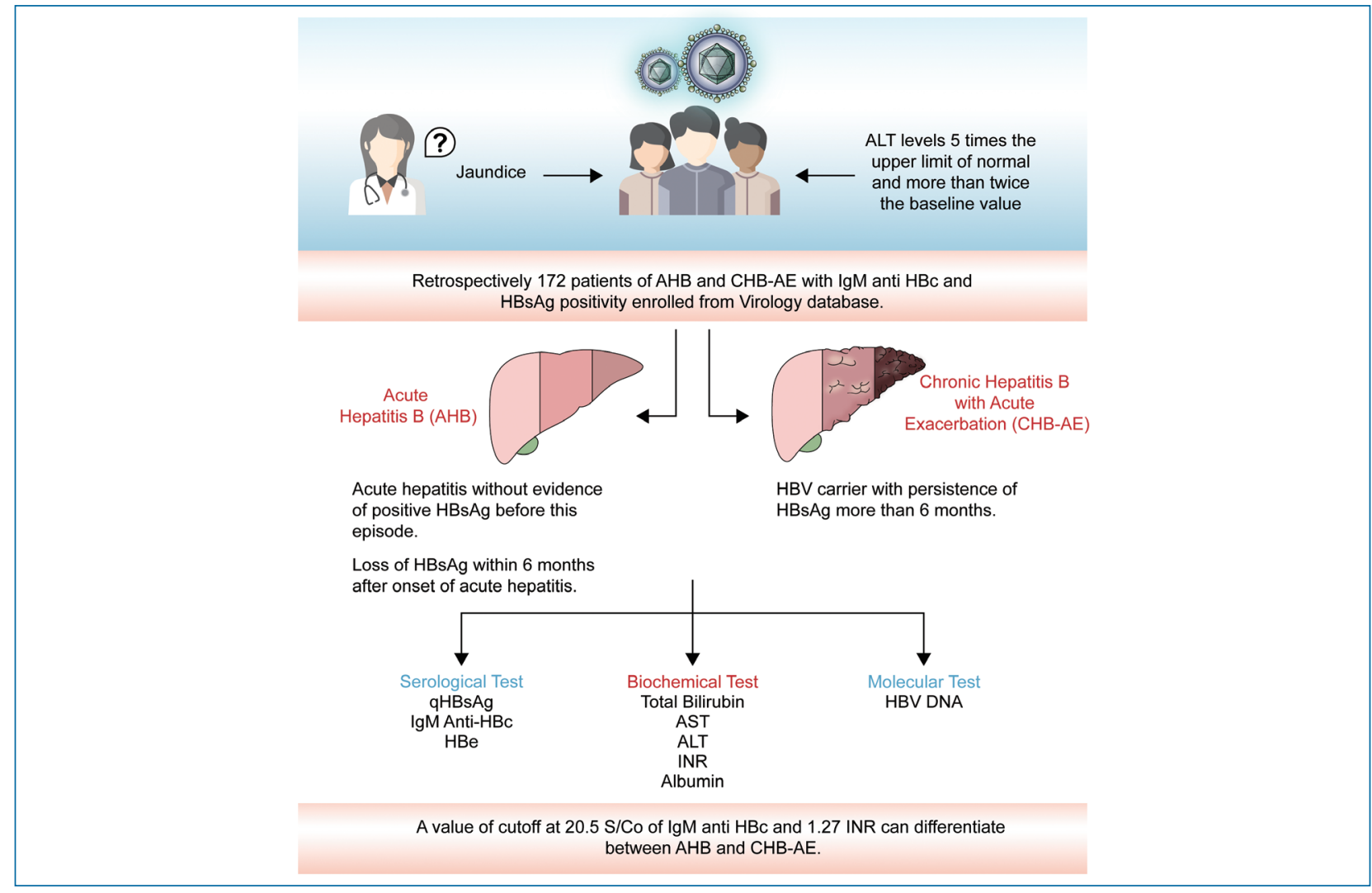

\section{Abbreviations:}

AHB, acute hepatitis B; ALT, alanine aminotransferase; anti-HBe, antibody to HBeAg; APASL, Asian Pacific Association for the Study of the Liver; APRI, AST platelet ratio index; AST, aspartate aminotransferase; AUROC, areas under ROC; CHB-AEs, acute exacerbations in chronic hepatitis B; CLIA, Chemiluminescence Immunoassay; $\mathrm{HBeAg}$, hepatitis B e antigen; HBsAg, hepatitis B surface antigen; $\mathrm{HBV}$, hepatitis B virus; IgM anti-HBC, immunoglobulin $\mathrm{M}$ antibody to the hepatitis $B$ core antigen; INR, international normalized ratio; NPV, negative predictive value; PEI, Paul-Ehrlich Units; PPV, positive predictive value; qHBsAg, quantitative HBsAg; RLUs, relative light units; ROC, receiver operating characteristic; S/Co, signal cut-off; SPSS, Statistical Package for the Social Sciences

\section{Corresponding author : Ekta Gupta}

Department of Clinical Virology, Institute of liver and Biliary Sciences, Delhi 110070, India

Tel: +91-9899975974, Fax: +91 1126123501

E-mail: ektagaurisha@gmail.com

https://orcid.org/0000-0002-5237-216X 
Background/Aims: Acute exacerbations of chronic hepatitis B (CHB-AEs) are common in endemic areas and are often presumed to be acute hepatitis B (AHB) due to their similarities in clinical and serological pictures, presenting a major diagnostic dilemma. This study aimed to identify laboratory markers for differentiating between the two groups, and to establish the cut-off value for significant markers.

Methods: A retrospective analysis of records was conducted for patients who presented with clinical features of acute hepatitis along with hepatitis $B$ surface antigen $(\mathrm{HBsAg})$ and $\lg M$ antibody to hepatitis $B$ core antigen (IgM anti- $\mathrm{HBC}$ ) positivity from May 2015 to May 2017. A total of 172 patients were enrolled and grouped as AHB $(n=89)$ and CHB-AE $(n=83)$ based on their history of hepatitis B virus infection and duration of $\mathrm{HBsAg}$ persistence. Virological and biochemical parameters were analyzed and compared. Cut-off values, sensitivity, and specificity of the variables were calculated.

Results: The median value of signal by cut-off ( $\mathrm{S} / \mathrm{Co}$ ) ratio for $\mathrm{IgM}$ anti-HBc was significantly higher in AHB group (30.44) compared to CHB-AE group (8.63) with a sensitivity and specificity of $97 \%$ and $84 \%$, respectively, at a cut-off of 20.5 $(P<0.01)$. The mean international normalized ratio (INR) was significantly greater in CHB-AE (1.88 \pm 1.24$)$ group compared to AHB group (1.62 \pm 0.17$)$ with a sensitivity and specificity of $57.9 \%$ and $45.1 \%$, respectively, at a cut-off value of 1.27 .

Conclusions: A value of $20.5 \mathrm{~S} / \mathrm{Co}$ of IgM anti-HBc and 1.27 INR could be helpful in differentiating between $\mathrm{AHB}$ and CHB-AE. (Clin Mol Hepatol 2020;26:187-195)

Keywords: Hepatitis B virus; Acute hepatitis; Chronic hepatitis; Distinction

\section{Study Highlights}

This study investigated whether quantitative serology is valuable in differentiating acute hepatitis B (AHB) from chronic hepatitis B with acute exacerbation (CHB-AE). A total of 172 patients were included and divided into two groups: AHB (89, 51.7\%) and CHB-AE (83, 48.3\%). The median value of signal by cut-off ( $\mathrm{S} / \mathrm{CO}$ ) ratio of IgM anti-HBc was significantly higher (30.44 vs. 8.63), and the mean value of INR was significantly lower (1.62 $\pm 0.17 \mathrm{vs.}$ $1.88 \pm 1.24$ ) in AHB group compared to CHB-AE group (all $P<0.05$ ). The results of this study suggest that quantitative serologic markers could be helpful in the diagnosis of patients with HBV infection.

\section{INTRODUCTION}

Hepatitis B virus (HBV) infection is a substantial global health problem, with more than 2 billion people infected worldwide and 257 million cases being chronic hepatitis. ${ }^{1,2}$ In India, it is estimated that about 40 million people are chronically infected with the virus, with a prevalence of $3.7 \%{ }^{3}$ HBV infection results in a spectrum of disease entities ranging from asymptomatic carrier state to the most severe form of chronic active hepatitis B. ${ }^{4}$

A large percentage of patients with chronic active hepatitis may frequently show a changing pattern, including acute exacerbations in liver injury along with episodes of normal liver function. This reflects the dynamic interplay between the immune response of human body and viral replication. ${ }^{5}$ According to the 2015 Asian Pacific Association for the Study of the Liver (APASL) clinical practice guidelines on the management of hepatitis $B$, acute exacerbations in chronic hepatitis B (CHB-AEs) are usually defined as intermittent elevations of aminotransferase to more than five times the upper limit of normal and more than twice the baseline value. ${ }^{6}$ In HBV endemic areas, CHB-AEs are common and may often be the first sign of the disease. Over $50 \%$ of such patients are presumed to have acute hepatitis B (AHB) due to similar clinical and serological pictures, thereby posing a major diagnostic dilemma. ${ }^{7-10}$

The need to differentiate between CHB-AE and AHB is worthy of our attention due to their different prognosis which requires different types of therapeutic intervention. Most of the patients with AHB show complete clinical improvement and resolve spontaneously. Only a small number of those with severe/fulminant disease may require treatment while those with CHB-AE usually require therapy for hepatic decompensation, and high mortality may occur as a result of hepatocellular dysfunction. ${ }^{11}$ Here, a simple and reliable serological marker would come in handy to differentiate between these two conditions. The amount of available data on the use of serological assays in diagnosing CHB-AE is very limited, and there are variations in the inclusion and differentiation criteria of different studies. Immunoglobulin $\mathrm{M}$ antibody to the hepatitis B core antigen ( $(\mathrm{gM}$ anti-HBC) has been considered an important diagnostic marker for AHB. ${ }^{12,13}$ However, since about $20 \%$ to $27.5 \%$ of CHB-AE patients have IgM anti-HBc positivity with the fully automated, quantitative analysis method, these pa- 
tients could clinically present as AHB ${ }^{10}$ Therefore, a simple, effective, and reliable serological marker with a cut-off value is required to differentiate between these two conditions. Very few studies on this topic have been conducted in India. In this study, we aimed to identify the difference in serological markers of $A H B$ and CHB-AE, and to figure out an optimal cut-off value for the serological monitoring of HBV.

\section{MATERIALS AND METHODS}

This study was performed at a tertiary care liver center in India. After the approval from the Institutional Ethics Committee (IEC/2018/58/MA03) and review board, a retrospective analysis of records was done on all patients who presented with acute viral hepatitis with hepatitis B surface antigen ( $\mathrm{HBsAg}$ ) and IgM antiHBC positivity between May 2015 and May 2017. ${ }^{6}$ Detailed clinical information regarding the onset of illness, presenting signs and symptoms, and previous history of such episodes of HBV infection were obtained from the Hospital Information System. Patients coinfected with hepatitis A virus, hepatitis C virus, hepatitis E virus, and human immunodeficiency virus were excluded from the study. After careful review of the subjects' history as well as their clinical and serological profiles, 172 patients were included and divided into two groups: AHB $(89,51.7 \%)$ and CHB-AE (83, 48.3\%). AHB group included patients with clinical signs and symptoms of $A H B$ without a history of past HBV infection, as well as HBsAg not persisting for more than 6 months. CHB-AE group included HBV carriers with HBsAg antigen persisting for more than 6 months, who had more than five times the upper limit of normal and more than twice the baseline value of aminotransferase. Baseline characteristics such as age, sex, and biochemical parameters including serum levels of total bilirubin, aspartate aminotransferase (AST), alanine aminotransferase (ALT), AST/ALT ratio, international normalized ratio (INR), AST platelet ratio index (APRI) score, and albumin, were noted. Out of 83 patients from CHB-AE group, 60 (72.2\%) were cirrhotic and 23 (27.7\%) were non-cirrhotic using 1.5 as the higher cut-off of APRI score. Biochemical and virological profiles of the two groups were compared to establish the diagnostic markers for their differentiation.

Various serological markers, such as IgM anti-HBc, quantitative HBsAg (qHBsAg), hepatitis B e antigen (HBeAg), and antibody to $\mathrm{HBeAg}$ (anti-HBe), were tested on commercial Chemiluminescence Immunoassay (CLIA)-based platform (Architect i1000SR; Abbott Diagnostics, Abbott Park, IL, USA). Chemiluminescence immunoassay on the Abbott Architect is a two-step immunoassay with flexible assay protocols called chemiflex, which utilizes paramagnetic particles coated with the respective antigen/antibodies to which human serum is incubated. After washing, acridine-labelled conjugate was added followed by pre-trigger and trigger solutions, and the resulting chemilluminiscent reaction was measured as relative light units (RLUs). A direct relationship was shown between the amount of analyte in the sample and the RLUs detected by Architect System optics. Results were calculated as normalized

Table 1. Comparison of host parameters between groups

\begin{tabular}{|c|c|c|c|}
\hline Variable & AHB & CHB-AE & $P$-value \\
\hline Male/female & $66 / 23$ & $65 / 18$ & 0.52 \\
\hline Age (years) & $43 \pm 16$ & $43 \pm 17$ & 0.95 \\
\hline Total bilirubin (mg/dL) (NR, 0.1-1.2) & $17.7(7.1-22.9)$ & $15.4(4.3-26.5)$ & 0.996 \\
\hline AST (IU/L) (NR, 10-40) & $529(193-1,021)$ & $221(93-269)$ & $<0.001$ \\
\hline ALT (IU/L) (NR, 7-56) & $664(177-1,243)$ & $168(87-583)$ & $<0.001$ \\
\hline AST/ALT & $0.98 \pm 0.09$ & $1.03 \pm 0.11$ & 0.18 \\
\hline INR & $1.62 \pm 0.17$ & $1.88 \pm 1.24$ & 0.045 \\
\hline $\mathrm{Hb}(\mathrm{g} / \mathrm{dL})$ & $12.8 \pm 2.3$ & $12.0 \pm 2.3$ & 0.34 \\
\hline Platelet $\left(\times 10^{3} / \mu \mathrm{L}\right)$ & $224(151-272)$ & $213(111-291)$ & 0.09 \\
\hline Albumin $(\mathrm{g} / \mathrm{dL})$ & $3.2 \pm 0.8$ & $2.9 \pm 0.8$ & 0.01 \\
\hline APRI & $6.5(2.9-11.6)$ & $4.1(1.6-9.2)$ & 0.13 \\
\hline
\end{tabular}

Values are presented as mean \pm standard deviation or median (IQ range).

$A H B$, acute hepatitis $B$; CHB-AE, chronic hepatitis B with acute exacerbation; NR, normal range; AST, aspartate aminotransferase; ALT, alanine aminotransferase; INR, international normalized ratio; Hb, hemoglobin; APRI, AST platelet ratio index; IQ, interquartile range from the 25th (Q1) to the 75th (Q3) percentile. 
signal cut-off ( $\mathrm{S} / \mathrm{Co})$ ratios obtained by measuring the signal strength of sample and the signal strength of an internal cut-off. $\lg M$ anti-HBC positivity was defined by an $S / C o$ ratio $\geq 1.0$. The concentration of qHBsAg was determined using a previously generated Architect HBsAg calibration curve, which allows the quantitation of $\mathrm{HBsAg}$ from 0.05 to $250 \mathrm{IU} / \mathrm{mL}$. Further dilution of samples was done to quantitate higher values. $S / C 0 \geq 1$ was considered reactive for $\mathrm{HBeAg}$, while $\mathrm{S} / \mathrm{Co} \leq 1$ was considered as reactive for anti-HBe. Real time polymerase chain reaction was done for HBV DNA quantitation using COBAS TaqMan HBV test (Roche Diagnostics; GmbH, Mannheim, Germany), which has a lower limit of detection of $6 \mathrm{IU} / \mathrm{mL}$ and linear range of 29 to $1.1 \times 10^{8} \mathrm{IU} / \mathrm{mL}$.

\section{Statistical analysis}

Quantitative variables were expressed as mean \pm standard deviation, or as median with range. Qualitative variables were expressed as numbers with percentage. HBV DNA levels and qHBsAg values were logarithmically transformed for analysis. Statistical analysis was performed using Statistical Package for the Social Sciences (SPSS) software for Windows version 22.0 (IBM SPSS, Armonk, NY, USA). Categorical data were compared using chi square test or Fischer exact test, as appropriate. Continuous data between the two groups were compared using Student's $t$ test or Mann-Whitney test, as appropriate. $P$ value $<0.05$ was considered statistically significant. To identify the independent factors that were significantly associated with AHB, multiple logistic regression analysis was conducted using forward stepwise likelihood ratio. Selected variables with $P$ value $<0.05$ on univariate analysis were included in regression analysis. To determine the optimal cut-off value of the variables for differentiating AHB from CHB-AE, the receiver operating characteristic (ROC) curves were plotted. The areas under ROC (AUROC) curves of identified factors were calculated. The sensitivity, specificity, positive predictive value (PPV), and negative predictive value (NPV) were also calculated.

\section{RESULTS}

Baseline characteristics of the study population are described in Table 1. The enrolled population was divided into two groups: AHB $(89,51.7 \%)$ and CHB-AE $(83,48.3 \%)$. Both of the groups were comparable in all parameters except for AST and ALT being significantly higher in AHB group, reflecting the intensity of necroinflammation, and INR was significantly greater in CHB-AE group.

\section{Comparison of virological parameters}

Various viral markers were compared between the two groups (Table 2). To decrease the variability of data and make data conform more closely to the normal distribution, HBV DNA values were $\log$-transformed as $\log _{10} \mathrm{IU} / \mathrm{mL}$. No significant difference was found between AHB and CHB-AE patients in terms of median values of viral markers, based on semiquantitative analysis of test results. However, S/Co values between the two groups differed significantly in median levels of $\operatorname{lgM}$ anti- $\mathrm{HBC}$ (30.4 vs. 8.6, $P<0.001)$.

\section{Finding independent predictors for CHB-AE in comparison to AHB}

Multiple logistic regression analysis of various factors revealed higher IgM anti-HBc titers and low INR as independent predictors of AHB as compared to CHB-AE (Table 3). Greater than $80 \%$ of correct predicting capability was seen in the combination of these two markers.

Table 2. Comparison of virological markers between groups

\begin{tabular}{lccc}
\hline Variable & AHB $(\mathbf{n}=89)$ & CHB-AE $(\mathbf{n}=83)$ & P-value \\
\hline HBeAg, S/Co & $33.5(8.5-115.0)$ & $38.9(2.0-1,062.2)$ & 0.32 \\
qHBsAg $\left(\log _{10} \mathrm{IU} / \mathrm{mL}\right)$ & $4.1(3.3-4.7)$ & $1.1(3.3-4.4)$ & 0.42 \\
HBV DNA viral load $\left(\log _{10} \mathrm{IU} / \mathrm{mL}\right)$ & $4.6(3.4-5.6)$ & $4.3(5.8-3.2)$ & 0.75 \\
IgM anti-HBC, S/Co & $30.4 \pm 8.5$ & $8.6 \pm 11.1$ & $<0.001$ \\
\hline
\end{tabular}

Values are presented as median (IQ range) or mean \pm standard deviation. Values of qHBsAg and HBV DNA were log-transformed for analysis. $A H B$, acute hepatitis $B$; CHB-AE, chronic hepatitis B with acute exacerbation; HBeAg, hepatitis B e antigen; S/Co, signal cut-off; qHBsAg, quantitative hepatitis B surface antigen; HBV, hepatitis B virus; IgM anti-HBC, immunoglobulin $M$ antibody to hepatitis B core antigen; IQ range, interquartile range. 


\section{Diagnostic value of IgM anti-HBc and INR as independent predictors alone and in combination for the differentiation between AHB and CHB-AE}

To determine the cut-off value of IgM anti-HBC as a sensitive marker of AHB, ROC was plotted. Figure 1 shows AUROC (0.87) using the sensitivity of IgM anti-HBc at various cut-off points. The sensitivity and specificity for the cut-off value of 20.5 were $93.3 \%$ and $92.7 \%$, respectively, while PPV and NPV at this cut-off were $86.9 \%$ and $95.9 \%$, respectively. The diagnostic performance of various S/Co ratios of IgM anti-HBc was evaluated based on the distribution of patients in each group (Table 4). IgM anti-HBc S/Co

Table 3. Multivariate logistic regression analysis for predicting AHB in comparison to CHB-AE (both host and viral factors)

\begin{tabular}{lccc}
\hline Significant variable & $\boldsymbol{P}$-value & Odds ratio & $\begin{array}{c}\mathbf{9 5 \%} \text { confidence } \\
\text { interval }\end{array}$ \\
\hline IgM anti $\mathrm{HBC}, \mathrm{S} / \mathrm{CO}$ & $<0.001$ & 0.9 & $0.8-0.9$ \\
\hline INR & 0.01 & 1.8 & $1.1-2.2$ \\
\hline
\end{tabular}

$A H B$, acute hepatitis $B ; C H B-A E$, chronic hepatitis $B$ with acute exacerbation; IgM anti-HBC, immunoglobulin $\mathrm{M}$ antibody to hepatitis $B$ core antigen; $S / C 0$, signal cut-off; INR, international normalized ratio.

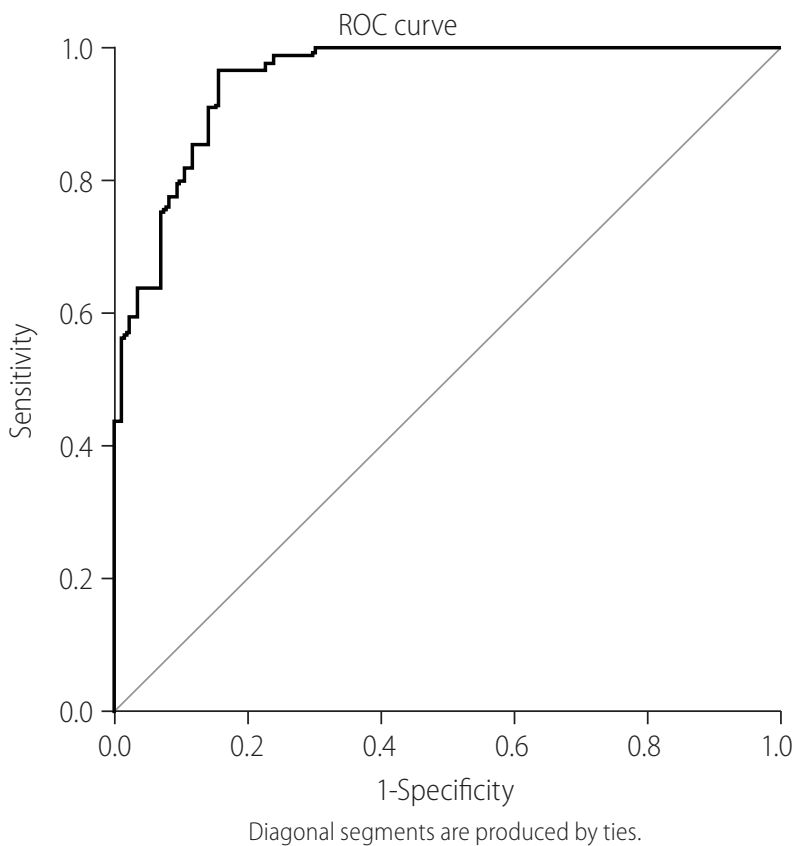

Figure 1. Receiver operating characteristic curve (ROC) plotted to determine the cut-off value of IgM anti-HBC as a sensitive marker of AHB. Figure shows the area under the ROC curve (AUROC) using the sensitivity of IgM anti-HBC at various cut-off points. IgM anti-HBC, immunoglobulin M antibody to hepatitis B core antigen; AHB, acute hepatitis B. ratios of $<10$ and $>30$ were found to be significant markers for CHB-AE and AHB, respectively $(P<0.001)$. To determine the cutoff value of INR as a sensitive marker of $A H B$, ROC was plotted. Figure 2 shows AUROC (0.56) using the sensitivity of INR at various cut-off points. The sensitivity and specificity for the cut-off value of 1.27 were $57.9 \%$ and $45.1 \%$, respectively. After combining these two markers, $A U R O C$ slightly increased to 0.90 , while sensitivity decreased to $80.2 \%$ and specificity remained almost the same (92.1\%; Fig. 3). These results showed that combining INR to IgM anti-HBc did not improve its predicting capability as an independent marker.

Table 4. Distribution of subjects with different $S / C$ o of IgM anti-HBC

\begin{tabular}{lccc}
\hline S/Co & AHB & CHB-AE & $P$-value \\
\hline$<10$ & 2 & 49 & $<0.001$ \\
$10-20$ & 12 & 17 & 0.23 \\
\hline $20-30$ & 27 & 8 & 0.14 \\
$>30$ & 48 & 9 & $<0.001$ \\
Total & 89 & 83 & 172 \\
\hline
\end{tabular}

$\mathrm{S} / \mathrm{Co}$, signal cut-off; IgM anti-HBc, immunoglobulin $\mathrm{M}$ antibody to hepatitis $B$ core antigen; $A H B$, acute hepatitis $B ; C H B-A E$, chronic hepatitis $B$ with acute exacerbation.

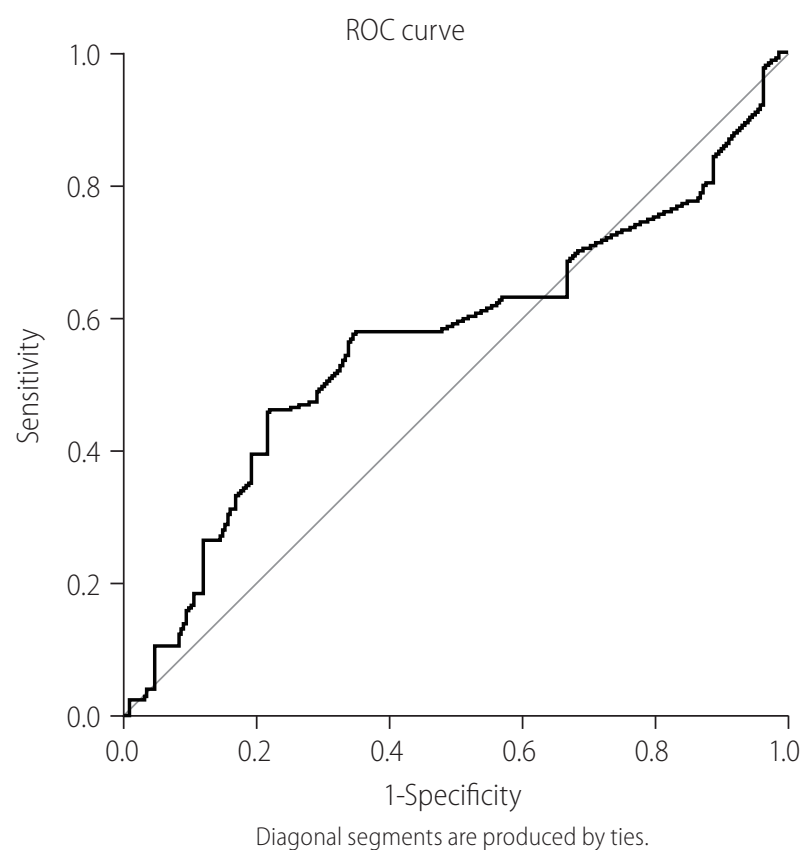

Figure 2. Receiver operating characteristic curve (ROC) plotted to determine the cut-off value of international normalized ratio (INR) as sensitive marker of acute hepatitis B. Figure shows the area under the ROC curve (AUROC) using the sensitivity of INR at various cut-off points. 


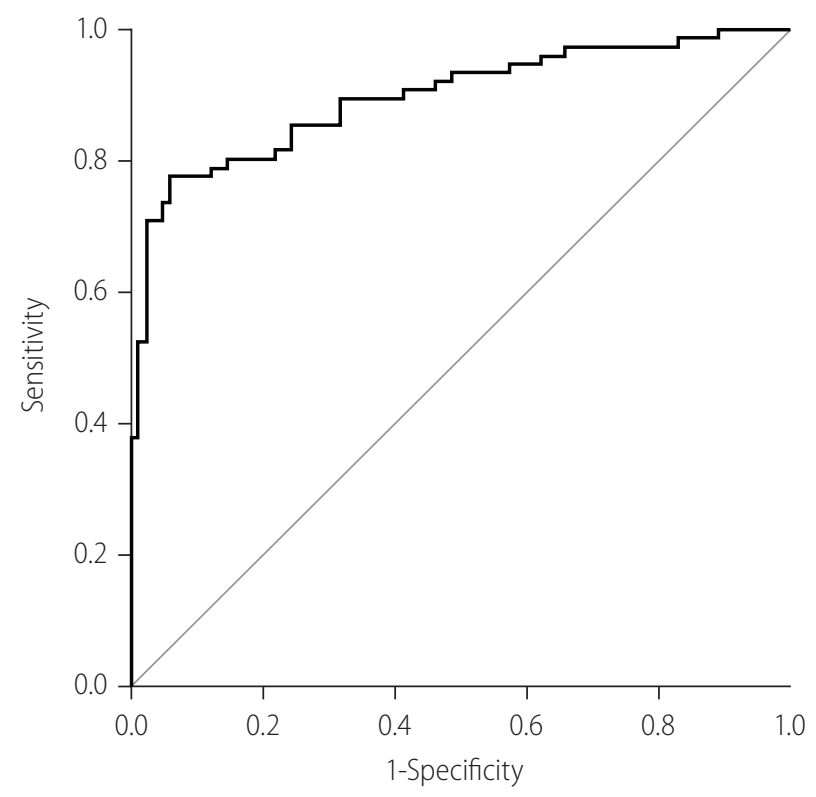

Area under ROC curve $=0.8965$

Figure 3. Receiver operating characteristic curve (ROC) plotted to determine the area under the ROC curve (AUROC) by using the sensitivity of combining international normalized ratio and IgM anti-HBC at their cut-off points. IgM anti-HBc, immunoglobulin $M$ antibody to hepatitis $B$ core antigen.

\section{Diagnostic value of HBV DNA levels for the differentiation between $A H B$ and CHB-AE}

Although the difference between the two groups for $\log _{10}$ HBV DNA values was not statistically significant, ROC was plotted to understand the role of HBV DNA levels as well as to find out the cut-off value of HBV DNA levels as a predictor of AHB. AUROC using $\log _{10}$ HBV DNA at various cut-off points was calculated. A cut-off value of $\leq 10.5 \log _{10} \mathrm{IU} / \mathrm{mL}$ could predict AHB with a sensitivity of $51.3 \%$, specificity of $51.4 \%$, and PPV of 50.7 . HBV DNA viral load was not significantly different between the two groups.

\section{Role of combining virological markers in the differentiation between $\mathrm{AHB}$ and $\mathrm{CHB}-\mathrm{AE}$}

The diagnostic efficacy of serological markers, such as qHBsAg, $\mathrm{HBeAg}$, and HBV DNA, in combination with IgM anti-HBC at their respective cut-off points was analyzed. After combining a cut-off of $10.5 \log _{10} \mathrm{IU} / \mathrm{mL}$ for HBV DNA and $2.7 \log _{10} \mathrm{IU} / \mathrm{mL}$ for qHBsAg, the sensitivity increased from $97.8 \%$ to $98.9 \%$ while the specificity significantly decreased from $51.8 \%$ to $49.1 \%$, as compared to using IgM anti-HBc alone. Similarly, by combining $\mathrm{HBeAg} S / C 0$ (cut-off value of 1.5), the specificity also decreased (13.8\%). These results showed that combining virological markers did not prove to be a better indicator to differentiate AHB from CHB-AE, as compared to using IgM anti-HBc alone.

\section{DISCUSSION}

The present study was performed to understand the role of various virological markers in differentiating AHB from CHB-AE. Both AHB and CHB-AE resemble each other in clinical presentation as well as in terms of biochemical characteristics. For differentiating this scenario on initial presentation, appropriate clinical history of the patients is required to highlight the onset of symptoms, of which is often lacking and thus isn't helpful in many cases. ${ }^{14}$ For numerous decades, the qualitative estimation of serological markers of hepatitis B infection has been the mainstay of diagnosis, in addition to the evaluation of AST and HBV DNA. Qualitative estimation using old enzyme immunoassays, which are usually standardized at a higher threshold values, lack the sensitivity to detect the variable at lower concentrations; furthermore, AST values lack specificity that represents the state of hepatic necrosis only. ${ }^{15}$ For many years, IgM anti-HBc was considered a specific marker for AHB due to the old assays that were standardized at $600-700$ PEI (Paul-Ehrlich Units) or avidity index, which detected only high values. However, with the help of the latest diagnostic techniques like chemiluminescence, quantitation of this parameter on wellcharacterized specimens of acute and CHB revealed a considerable percentage of positive cases among chronic hepatitis cases, but with lower levels. This has been demonstrated in various studies, as shown in Table $5 .^{16-20}$

In our study, the median levels of IgM anti-HBC and INR were found to be significantly different between the two groups, and also proven to be a sensitive predictor for AHB group. The result of the present study is in accordance with previous studies, which used different methods of quantification for IgM anti-HBC against semiquantitative serology. ${ }^{16-20}$ Higher $\lg \mathrm{M}$ anti-HBC titers suggest a highly active immune response which promotes $B$ cell differentiation into IgM producing plasmablasts. Since our hospital is a tertiary care liver institute, the presentation of majority cases in early acute phase of the illness can be responsible for the higher cut-off value obtained in our study, or it can also be due to the inherent immunological difference by region. The serum level of INR, which reflect the degree of coagulopathy in a patient with hepatic disease, was an independent predictor for AHB, although it had a 
Table 5. Comparative analysis of various studies evaluating the role of serology for differentiating between AHB and CHB-AE

\begin{tabular}{|c|c|c|c|c|c|}
\hline Study & Year/location & Technique & $\lg \mathrm{M}$ anti $\mathrm{HBC}$ & HBV DNA & Other relevant findings \\
\hline Rodella et al. ${ }^{16}$ & 2006/Italy & $\begin{array}{l}\text { Chemilluminiscent } \\
\text { immunoassay }\end{array}$ & $\begin{array}{l}S / C O=10, \text { avidity } \\
\text { index }=0.7 \text { diagnostic } \\
\text { for } A H B\end{array}$ & Not done & $\begin{array}{l}\text { HBsAg levels differed } \\
\text { significantly } A H B>C H B-A E\end{array}$ \\
\hline Huang et al. ${ }^{17}$ & 2006/Taiwan & $\begin{array}{l}\text { Serology: MEIA } \\
\text { HBV DNA-qPCR }\end{array}$ & $\begin{array}{l}\text { Mean index value } 2.9 \mathrm{AHB} \\
\text { vs. 1.5 CHB-AE }\end{array}$ & Comparable in both groups & $\begin{array}{l}\text { Cut-off for lgM anti-HBc } \\
2.4-2.5 \text { showed sensitivity } \\
\text { and specificity } 90 \%\end{array}$ \\
\hline Han et $a l^{18}$ & 2008/Shanghai & $\begin{array}{l}\text { Serology: enzyme } \\
\text { immunoassay } \\
\text { HBV DNA: qPCR }\end{array}$ & $\begin{array}{l}\text { At 1:10,000 titer high } \\
\text { sensitivity and } \\
\text { specificity of } 96.2 \% \text { and } \\
93 \%\end{array}$ & No significant difference & $\begin{array}{l}\text { Combining HBV DNA + } \\
\text { HBeAg increases diagnostic } \\
\text { power } \\
\text { Low HBeAg level more useful } \\
\text { than negative HBeAg }\end{array}$ \\
\hline Kumar et al. ${ }^{19}$ & 2006/India & $\begin{array}{l}\text { Enzyme } \\
\text { immunoassay }\end{array}$ & $\begin{array}{l}\text { Titer }>1: 1,000 \text { seen in } 80 \% \\
\text { people of AHB }\end{array}$ & $\begin{array}{l}<0.5 \mathrm{pg} / \mathrm{mL} \\
\text { Seen in CHB-AE }\end{array}$ & \\
\hline Dao et al. ${ }^{20}$ & 2012 & $\begin{array}{l}\text { Enzyme } \\
\text { immunoassay }\end{array}$ & $\mathrm{S} / \mathrm{N}$ higher in $\mathrm{AHB}=88.2$ & $\begin{array}{l}3.9 \log _{10} \mathrm{IU} / \mathrm{mL} \text { vs. } 5.2 \log _{10} \\
\mathrm{IU} / \mathrm{mL} \text { for AHB vs. CHB-AE }\end{array}$ & $\begin{array}{l}\text { Cut point S/N ratio of } 5.0 \text { for } \\
\operatorname{lgM}\end{array}$ \\
\hline Park et al. ${ }^{21}$ & 2015 & $\begin{array}{l}\text { Chemilluminiscent } \\
\text { immunoassay }\end{array}$ & $\begin{array}{l}\text { S/Co ratio of IgM } \\
\text { Anti-HBC was significantly } \\
\text { higher in AHB group }\end{array}$ & $\begin{array}{l}\text { HBV DNA level was } \\
\text { significantly higher in } \\
\text { CHB-AE group }\end{array}$ & $\begin{array}{l}\text { The optimal cut-off values of } \\
\text { lgM anti-HBc and HBV DNA } \\
\text { levels for differentiating the } \\
\text { two conditions were } 8 \mathrm{~S} / \mathrm{Co} \\
\text { ratio and } 5.5 \log _{10} \mathrm{IU} / \mathrm{mL} \text {, } \\
\text { respectively }\end{array}$ \\
\hline
\end{tabular}

$A H B$, acute hepatitis $B ;$ CHB-AE, chronic hepatitis B with acute exacerbation; IgM anti-HBc, immunoglobulin $M$ antibody to hepatitis $B$ core antigen; HBV, hepatitis $B$ virus; $H B e A g$, hepatitis $B$ e antigen; $S / C 0$, signal cut-off; $q P C R$, quantitative real-time polymerase chain reaction; MEIA, microparticle enzyme immunoassay; $S / N$, signal by noise ratio; qHBsAg, quantitative hepatitis B surface antigen.

lesser sensitivity compared to IgM anti-HBC. This result could not be inferred in isolation of other coagulation parameters such as platelets, prothrombin time, and activated partial thromboplastin time. We could not follow up with the patients for evaluating the dynamic values of INR using the prescribed drug regimen. Further studies are required to confirm our findings.

The present study did not find any significant differences between HBV DNA levels of both groups. This was in contrast to other studies which reported higher levels of HBV DNA being associated with CHB-AE as compared to AHB. ${ }^{19-21}$ HBV DNA levels in CHB-AE group in our study were quite comparable to those of AHB group. This could be due to the non-immunosuppressed state of the subjects, rapid immune clearance following HBV reactivation, effect of antiviral treatment which suppresses viral replication, and misallocation of some subjects in the two groups, as they were not fully clinically assessed.

HBeAg positivity has been found more frequently in patients with acute infection than in those with chronic infection, but the difference is not statistically significant. ${ }^{22,23}$ The present study showed no significant difference between the values of HBeAg in the two groups. Recent data support the fact that high levels of
HBsAg are associated with viral replication and disease activity. In acute hepatitis, the levels of HBsAg are generally above $1 \times 10^{7} \mathrm{IU} / \mathrm{L}$, and they decrease in the recovery phase. ${ }^{24-26}$ Although a median value of qHBsAg (4.12 $\log _{10} \mathrm{IU} / \mathrm{mL}$ ) was higher in AHB than in CHB-AE $\left(1.09 \log _{10} \mathrm{IU} / \mathrm{mL}\right)$ in the present study, the association was not statistically significant. Various studies have reflected significantly higher values of qHBsAg for acute phase. ${ }^{16}$

The liver fibrosis status in the two groups was not compared using Fibroscan, FIB-4 index, and M2BPGi. However, the APRI score and AST/ALT ratio did not differ between the two groups. While AST/ALT ratio $>1$ is recommended as a predictor of cirrhosis and has sensitivity and specificity of $81.3 \%$ and $55.3 \%$, respectively, an APRI of more than 1.5 has AUROC of $80 \%$ and $89 \%$, respectively, for advanced fibrosis F3-F4 and cirrhosis. ${ }^{27-29}$ Numerous studies have highlighted that the data concerning the clinical utility of transient elastography in hepatitis B appears promising with $84 \%$ and $65 \%$ positive and NPVs, respectively, for a cut-off of 7.0 $\mathrm{kPa}$. Although acute hepatitis can produce false-positive results in the APRI, Forns index, FIB-4, or Fibrometer tests, which all measure the levels of aminotransferases, not much is present in the existing literature on differentiating AHB from CHB-AE using 
these markers. ${ }^{30}$

Although a few studies have highlighted the importance of combining IgM anti-HBC and HBV DNA to increase the sensitivity and specificity of newly created marker, the present study could not find such association. ${ }^{18}$ Although an increase in sensitivity was seen after combining IgM anti-HBc with qHBsAg, HBV DNA, and $\mathrm{HBeAg}$, the specificity decreased remarkably. This could be due to the fact that not all of the subjects in the study underwent testing for all serological markers during follow-up visits to the hospital.

In conclusion, CHB-AE causing derangement of liver functions may be seen in a flare of HBV during the immune clearance phase or HBV reactivation in patients with inactive hepatitis infection or resolved HBV infection. In endemic countries like India, the differentiation between CHB-AE and AHB is important for both prognostication and management of the disease. Quantitation of IgM anti-HBc can work as a simple marker of differentiation between $A H B$ and CHB-AE. Our analysis of various serological markers in this study showed that only lgM anti-HBc was a significant discriminating factor between $\mathrm{CHB}-\mathrm{AE}$ and $\mathrm{AHB}$, and that combining other markers did not add to its discriminating power.

\section{Study limitations}

The present study had some limitations due to its retrospective nature, and it was purely dependent on the patient information that were available in the hospital system. To find the best possible operational and feasible approach, the patients were retrospectively categorized into two groups based on their clinical history as well as the presence or absence of HBsAg antigen after 6 months. ${ }^{6,21,31}$ Also, the possibility of misclassification of cases cannot be negated, as the loss of HBsAg at exactly 6 months is not very commonly reported. Therefore, further studies are needed to highlight the role of serological markers in differentiating $A H B$ and CHB-AE. Furthermore, the evaluation of cut-off of IgM anti$\mathrm{HBC}$ by quantitative assay is recommended over the semiquantitative one used in this study for better statistical agreement, and INR results on serial follow-up would add more to our knowledge.

\section{Authors' contribution}

Ekta Gupta: Conception, designing, and supervision of work. Writing and revision of manuscript

Sujata Lall, Pragya Agarwala: Designing, writing, and revision of manuscript

Guresh Kumar: Statistical analysis and interpretation of data

Manoj Kumar Sharma: Critical revision of the manuscript

\section{Conflicts of Interest}

The authors have no conflicts of interest to disclose.

\section{REFERENCES}

1. World Health Organization (WHO). Hepatitis B. World health Organization Global hepatitis report 2017. WHO web site, <https://www. who.int/hepatitis/publications/global-hepatitis-report2017/en/>. Accessed 18 Jul 2017.

2. Lavanchy D. Hepatitis B virus epidemiology, disease burden, treatment, and current and emerging prevention and control measures. J Viral Hepat 2004;11:97-107.

3. Puri P. Tackling the hepatitis B disease burden in India. J Clin Exp Hepatol 2014;4:312-319.

4. Maruyama T, Schödel F, lino S, Koike K, Yasuda K, Peterson D, et al. Distinguishing between acute and symptomatic chronic Hepatitis $B$ virus infection. Gastroenterology 1994;106:1006-1015.

5. Maruyama T, lino S, Yasuda K, Milich DR. Serology of acute exacerbation in chronic hepatitis B virus infection. Gastroenterology 1993;105:1141-1151.

6. Sarin SK, Kumar M, Lau GK, Abbas Z, Chan HL, Chen CJ, et al. Asian-Pacific clinical practice guidelines on the management of hepatitis B: a 2015 update. Hepatol Int 2016;10:1-98.

7. Davis $G L$, Hoofnagle JH. Reactivation of chronic type $B$ hepatitis presenting as acute viral hepatitis. Ann Intern Med 1985;102:762-765.

8. Chu CM, Sheen IS, Liaw YF. The aetiology of acute hepatitis in Taiwan: acute hepatitis superimposed on HBsAg carrier state as the main aetiology of acute hepatitis in areas with high HBsAg carrier rate. Infection 1988;16:233-237.

9. Liaw YF, Chu CM, Huang MJ, Chen TJ, Lin DY. The etiology of acute viral hepatitis in an endemic area of hepatitis A and B. Am J Trop Med Hyg 1983:32:1401-1406.

10. Tassopoulos NC, Papaevangelou GJ, Sjogren MH, RoumeliotouKarayannis A, Gerin JL, Purcell RH. Natural history of acute hepatitis B surface antigen-positive hepatitis in Greek adults. Gastroenterology 1987;92:1844-1850

11. Puri P. Acute exacerbation of chronic hepatitis B: the dilemma of differentiation from acute viral hepatitis B. J Clin Exp Hepatol 2013;3:301-312.

12. Kryger P, Mathiesen LR, Aldershville J, Nielsen JO. Presence and meaning of anti-HBC IgM as determined by ELISA in patients with acute type $B$ hepatitis and healthy HBsAg carriers. Hepatology 1981;1:233-237.

13. Papaevangelou G, Roumeliotou-Karayannis A, Tassopoulos N, Stathopoulou P. Diagnostic value of anti-HBC IgM in high HBV prevalence areas. J Med Virol 1984;13:393-399.

14. Santos MV, Duarte MIS, Barone AA. Acute exacerbation in chronic 
hepatitis B virus infection. Rev Soc Bras Med Trop 1996;29:275-279.

15. Miller DJ. Seroepidemiology of viral hepatitis: correlation with clinical findings. Postgrad Med 1980;68:137-141, 144-148.

16. Rodella A, Galli C, Terlenghi L, Perandin F, Bonfanti C, Manca N. Quantitative analysis of $\mathrm{HBsAg}$, IgM anti- $\mathrm{HBC}$ and anti-HBC avidity in acute and chronic hepatitis B. J Clin Virol 2006;37:206-212.

17. Huang YW, Lin CL, Chen PJ, Lai MY, Kao JH, Chen DS. Higher cut-off index value of immunoglobulin $M$ antibody to hepatitis $B$ core antigen in Taiwanese patients with hepatitis B. J Gastroenterol Hepatol 2006;21:859-862.

18. Han $Y$, Tang $Q$, Zhu W, Zhang $X$, You L. Clinical, biochemical, immunological and virological profiles of, and differential diagnosis between, patients with acute hepatitis B and chronic hepatitis B with acute flare. J Gastroenterol Hepatol 2008;23:1728-1733.

19. Kumar M, Jain S, Sharma BC, Sarin SK. Differentiating acute hepatitis $B$ from first episode of symptomatic exacerbation of chronic hepatitis B. Dig Dis Sci 2006;51:594-599.

20. Dao DY, Hynan LS, Yuan HJ, Sanders C, Balko J, Attar N, et al. Two distinct subtypes of hepatitis $B$ virus-related acute liver failure are separable by quantitative serum immunoglobulin $M$ anti hepatitis B core antibody and hepatitis B virus DNA levels. Hepatology 2012;55:676-684.

21. Park JW, Kwak KM, Kim SE, Jang MK, Kim DJ, Lee MS, et al. Differentiation of acute and chronic hepatitis $B$ in $\operatorname{lgM}$ anti-HBc positive patients. World J Gastroenterol 2015;21:3953-3959.

22. Okada K, Kamiyama I, Inomata M, Imai M, Miyakawa Y. e antigen and anti-e in the serum of asymptomatic carrier mothers as indicators of positive and negative transmission of hepatitis $B$ virus to their infants. N Engl J Med 1976;294:746-749.

23. Hoofnagle JH, Dusheiko GM, Seeff LB, Jones EA, Waggoner JG,
Bales ZB. Seroconversion from hepatitis B e antigen to antibody in chronic type B hepatitis. Ann Intern Med 1981;94:744-748.

24. Frösner GG, Schomerus H, Wiedmann KH, Zachoval R, Bayerl B, Bäcker $U$, et al. Diagnostic significance of quantitative determination of hepatitis B surface antigen in acute and chronic hepatitis B infection. Eur J ClinMicrobiol 1982;1:52-58.

25. Chulanov VP, Shipulin GA, Schaefer S, Gerlich WH. Kinetics of HBV DNA and HBsAg in acute hepatitis B patients with and without coinfection by other hepatitis viruses. J Med Virol 2003;69:313-323.

26. Chen $\mathrm{CH}$, Lee CM, Wang JH, Tung HD, Hung CH, Lu SN. Correlation of quantitative assay of hepatitis $B$ surface antigen and HBV DNA levels in asymptomatic hepatitis B virus carriers. Eur J Gastroenterol Hepatol 2004;16:1213-1218.

27. Giannini E, Risso D, Botta F, Chiarbonello B, Fasoli A, Malfatti F, et al. Validity and clinical utility of the Aspartate aminotransferasealanine aminotransferase ratio in assessing disease severity and prognosis in patients with hepatitis C virus-related chronic liver disease. Arch Intern Med 2003;163:218-224.

28. Sebastiani G, Vario A, Guido M, Alberti A. Sequential algorithms combining non-invasive markers and biopsy for the assessment of liver fibrosis in chronic hepatitis B. World J Gastroenterol 2007;13: 525-531.

29. Wai CT, Greenson JK, Fontana RJ, Kalbfleisch JD, Marrero JA, Conjeevaram $\mathrm{HS}$, et al. A simple noninvasive index can predict both significant fibrosis and cirrhosis in patients with chronic hepatitis C. Hepatology 2003;38:518-526.

30. Castera L. Noninvasive methods to assess liver disease in patients with hepatitis B or C. Gastroenterology 2012;142:1293-1302.e4.

31. Jindal A, Kumar M, Sarin SK. Management of acute hepatitis $B$ and reactivation of hepatitis $B$. Liver Int 2013;33 Suppl 1:164-175. 